Report:

\title{
A Tribute to Dr. Seyed Ali Fakhr Tabatabaei: A Legendary Neurosurgeon
}

\author{
Zahid Hussain Khan ${ }^{1}$ (D), Mehdi Zeinalizadeh ${ }^{2 *}$ (D)
}

1. Department of Anesthesiology and Critical Care, Imam Khomeini Hospital Complex, Tehran University of Medical Sciences, Tehran, Iran

2. Department of Neurological Surgery, Imam Khomeini Hospital Complex, Tehran University of Medical Sciences, Tehran, Iran

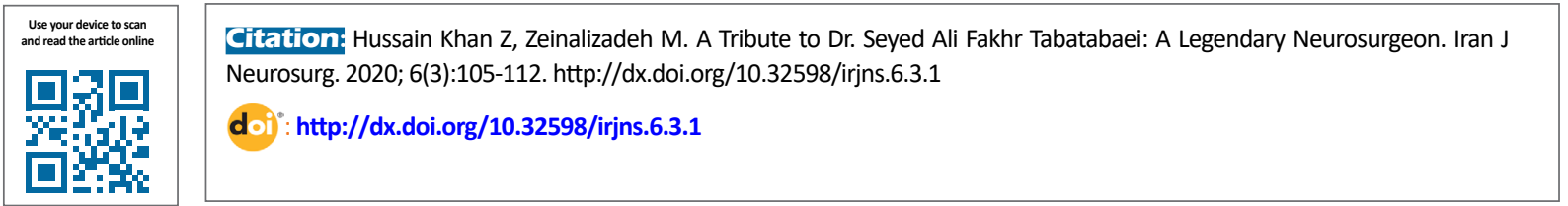

\section{Biodata in a Nutshell}

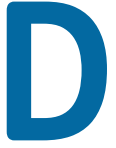

r. Seyed Ali Fakhr Tabatabaei was born in Garmsar, a small city in the Southeast of the capital, Tehran on November 27, 1947. He finished his primary school in his hometown Garmsar (Figure 1) and later finished his secondary education in 1966. In 1973, he obtained his M.D. from Tehran University, and in the same year passed his ECFMG. From 1973 till 1975, he served his compulsory military service in the country (Figure 2).

After having finished his residency in neurosurgery at Tehran University of Medical Sciences (TUMS), he was declared a qualified neurosurgeon in 1979. In 1981, he was appointed as an Assistant Professor in neurosurgery and initiated his work as a faculty member in the neurosurgical department of Imam Khomeini Hospital Complex (IKHC), Tehran, Iran. In 1992, he was promoted to the rank of Associate Professor, and 10 years later in 2002, he was promoted to the rank of Professorship (Figure 3).

During this period, he availed of sabbatical leave and proceeded for advanced training in microsurgery as a research fellow from 1988-1989 at the University of Pittsburgh, USA, under the patroonship of professor Peter Jannetta (Figure 4A \& 4B). He retired from TUMS in 2009 after having served as an exemplary teacher and a valuable mentor.
Mountaineering has been his hobby since his student days which he has continued and maintained till today (Figure 5A \& 5B). He got married to Dr. Firouzeh Nilli in May 1991 (Figure 6). Dr. Nilli was a pediatric resident when the marriage took place. She later joined the department of pediatrics and retired as a professor of pediatric neonatology.

\section{As a Faculty Member at the Neurosurgical Department, IKHC}

In the year 1985, he became the head of the neurosurgical department, a position he maintained till his retirement in the year 2009. In the year 1988, he established a separate neurosurgical ICU catered for neurosurgical cases. Prior to that neurosurgical cases used to be admitted to the general ICU. He had been an active member of the Iranian Board of Neurosurgical Examinations from 1988 till the date he was retired.

\section{As a Teacher}

Ever since his appointment as an Assistant Professor, he has been actively involved in teaching both the undergraduates and the residents. For the medical students, he used to present comprehensive lectures twice a year about neuroanatomy and brain tumors. His classes were always jam-packed and students were awed by

* Corresponding Author:

Mehdi Zeinalizadeh, MD.

Address: Department of Neurological Surgery, Imam Khomeini Hospital Complex, Tehran University of Medical Sciences, Tehran, Iran

Tel: +98 (21) 66591320

E-mail: mzeinalizadeh@tums.ac.ir 


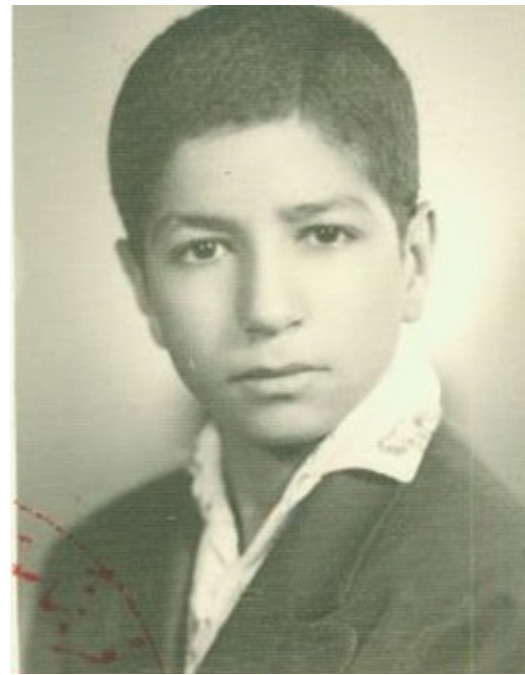

Figure 1. After finishing his primary school

his deep understanding of the subjects he taught. Most of those students later on, after graduation joined the neurosurgical residency program and followed the footsteps of their devoted teacher and mentor.

For the residents, he used to conduct weekly lectures and marathon rounds of all the patients admitted to the wards and the emergency department. It was a special moment to watch him in the wards and the hospital premises followed by his students and residents in a row. It reflected his enthusiasm to look at all the case sheets, images, and laboratory data with an eagle's eye so as not to miss a single pre-operative note or a postoperative complication. This habit, he inculcated in his junior faculty staff.

As a mentor and teacher, he was too good, and that is the reason, he can be rightly called a living legend and an iconic figure in the national history of neurosurgery. Besides, teaching and imparting the science of surgery to his residents, he was deeply interested in their overall well-being and helped them if they had any problems or shortcomings in their daily life.

\section{Technical and Practical Expertise}

Because of his in-depth knowledge of neuroanatomy and neurology, his surgical aptitude was also exemplary. Since he knew in detail the basic concepts of the disease, he would always opt for the most plausible and practicable approach as far as surgery was concerned. It reminds us of William Osler, the renowned physician who said "What the mind does not know, the eyes cannot see". Dr. Tabatabaei knew and fully understood the minutest details which was the reason that helped him

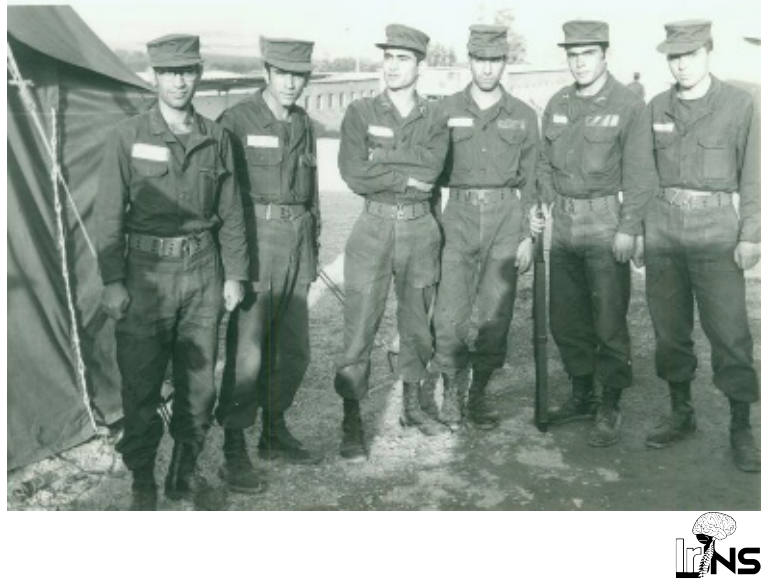

Figure 2. Third from right, dressed in military uniform after graduation

to execute challenging surgeries with exactness and good outcome. While performing surgery, he would wholeheartedly impart the intricacies and delicacies of the surgical steps to his junior faculty staff and residents.

\section{Research Activities}

He conducted a host of research programs such as the applicability of omental graft in experimentally induced spinal cord compression in rats. Besides, he supervised more than 50 medical theses both at the undergraduate and residency levels.

He has, to his credit, many papers published in renowned journals. Some of these papers were published while he was at Pittsburgh with the collaboration of his colleagues Younas, Segal, Alsawaf, Satto, and Mckinstry. These publications along with those published with the authors of this paper, Hussain Khan and Zeinalizadeh [1-8].

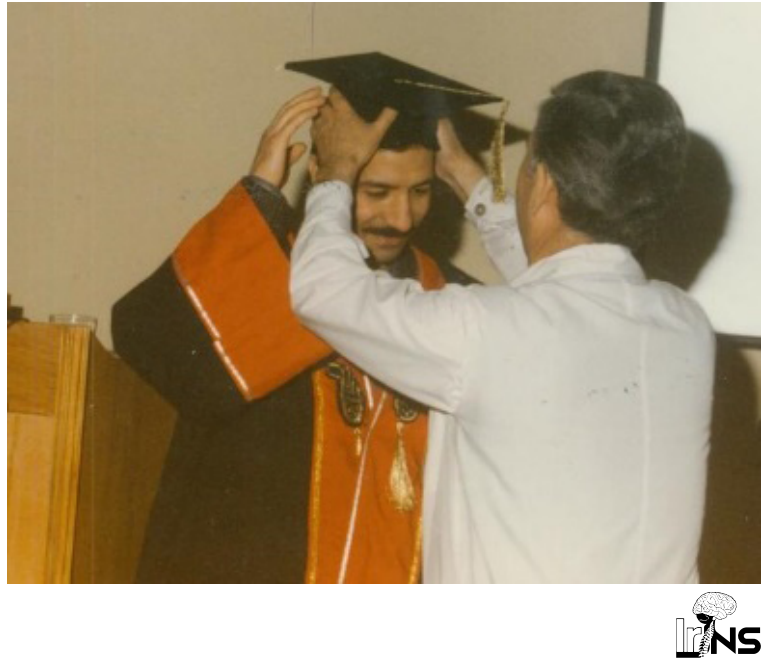

Figure 3. Being promoted to the highest rank of professorship 


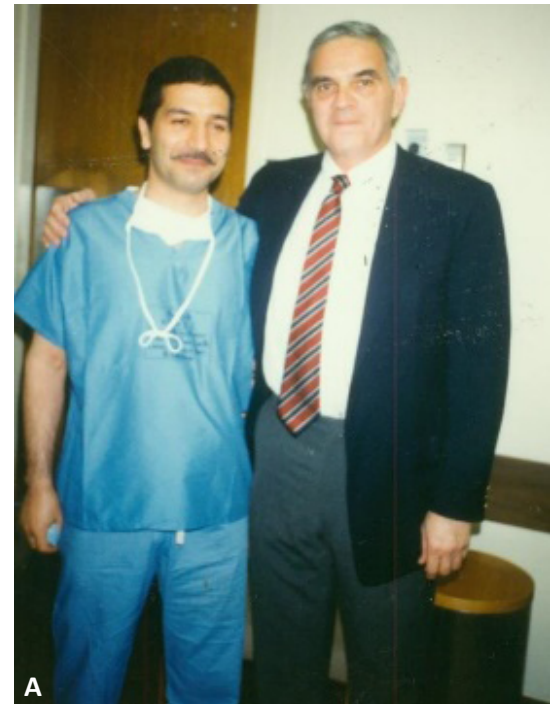

Figure 4. A \& B: With his mentor late Professor Peter Jannetta

He had a taste for research and writing which was the reason that he wrote two books in English (Figure 7A \& 7B) and two books in Persian (Figure 7C), about head injuries, applied neuroanatomy, and clinical neuroanatomy.

\section{Presentations at the National and Interna- tional Levels}

He had the habit of compiling all his data and would present them in symposiums and congresses. He presented his papers at the annual congresses of neurosurgery in Seattle, New Delhi, Moscow, Acapulco, Berlin, Sydney, Morocco, and many other places (Figure 8). Besides presenting his works at the International level, he has also actively participated in the annual congresses in Tehran and many times presided over the congress

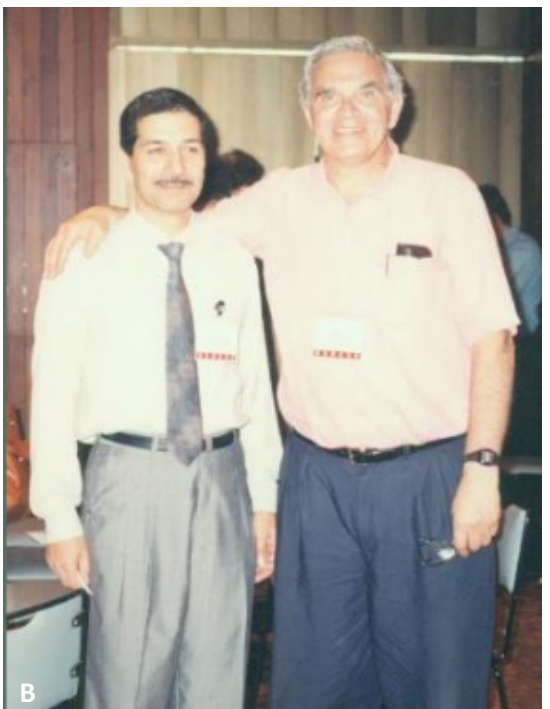

No

as a moderator or a speaker. Ever since its inception in 1981, the Annual Congress of Neurosurgery had been an academic event lasting 5 days where Dr. Tabatabaei has always been a keynote speaker (Figure 9).

\section{As the Head of the Department}

He has always had his unique style of running the neurosurgical department with his professional and intellectual rigor which is evident in several new initiatives that he has introduced.

With characteristic scholarship and precision, his initiatives and innovative works in the neurosurgical department helped in the current understanding of the surgical approach to tumors at the cerebellopontine
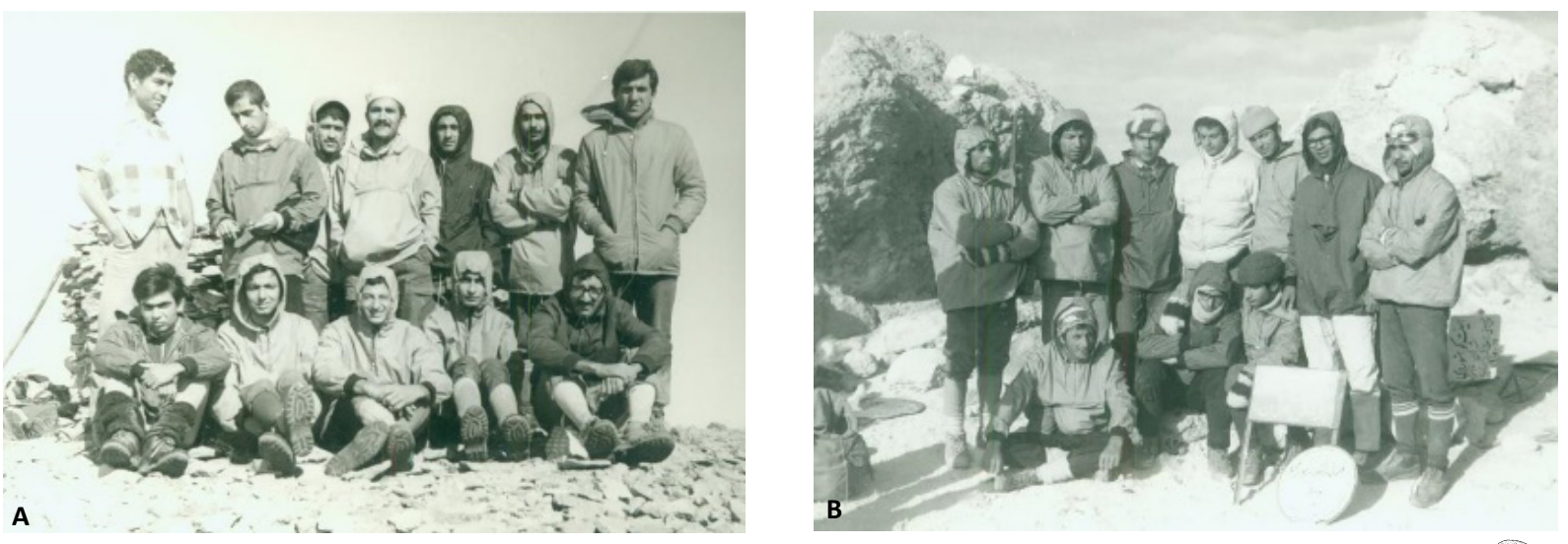

Figure 5. A: Upper row, first from left, at Somamos mountain top located at the south of Ramsar city and the border of the 2 northern provinces of Iran, Mazandaran, and Guilan); B: Upper row, second from left, at mount Damavand's peak (at $70 \mathrm{~km}$ northeast of Tehran and $70 \mathrm{~km}$ south of the Caspian Sea, the highest peak in Iran and the Middle East). 


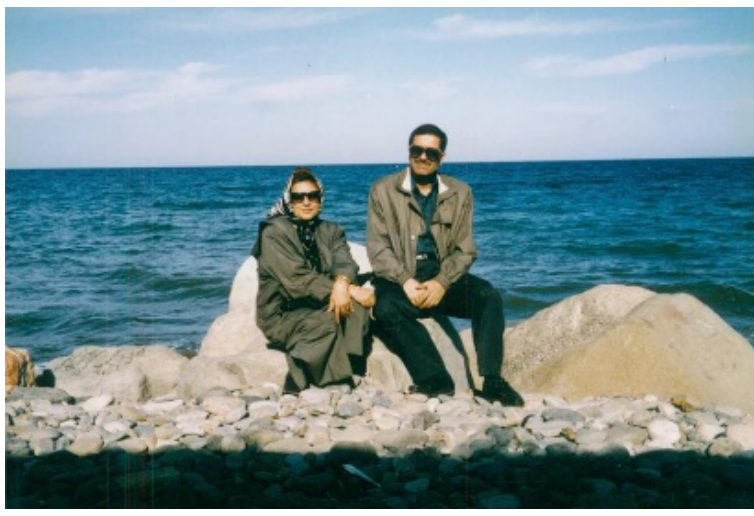

Figure 6. With his wife, Dr. Nilli

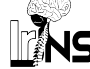

angle such as neurinoma, schwannoma, trigeminal neuralgia, hemifacial spasm, deep-seated aneurysm, arterio-venous malformations, and pituitary adenomas.
After returning from Pittsburgh, he literally revolutionized the surgical approach to TGN (trigeminal neuralgia) and HFS (hemifacial spasm) from the experience he had gained while at Pittsburgh from his mentors Peter Jannetta, Paul B. Nelson, and others (Figures 4 and 10).

He had been a helpful source of inspiration for the students, residents, and faculty staff. He was a kind advisor and all benefited from his wisdom and knowledge of neuroanatomy and neurosurgical practice. His trained residents are currently working in the department as faculty members and others are engaged in neurosurgical practice along the length and breadth of the country

Dr. Tabatabaei always displayed his extreme respect to his elders in the neurosurgical department such as Professor Ebrahim Samii (the founder of the department), Professor Murshid, and Professor Alimohamadi (Figure $11 \mathrm{~A}-\mathrm{C})$, and always sought their advice when confronted with challenging cases in neurosurgery or else in mat-
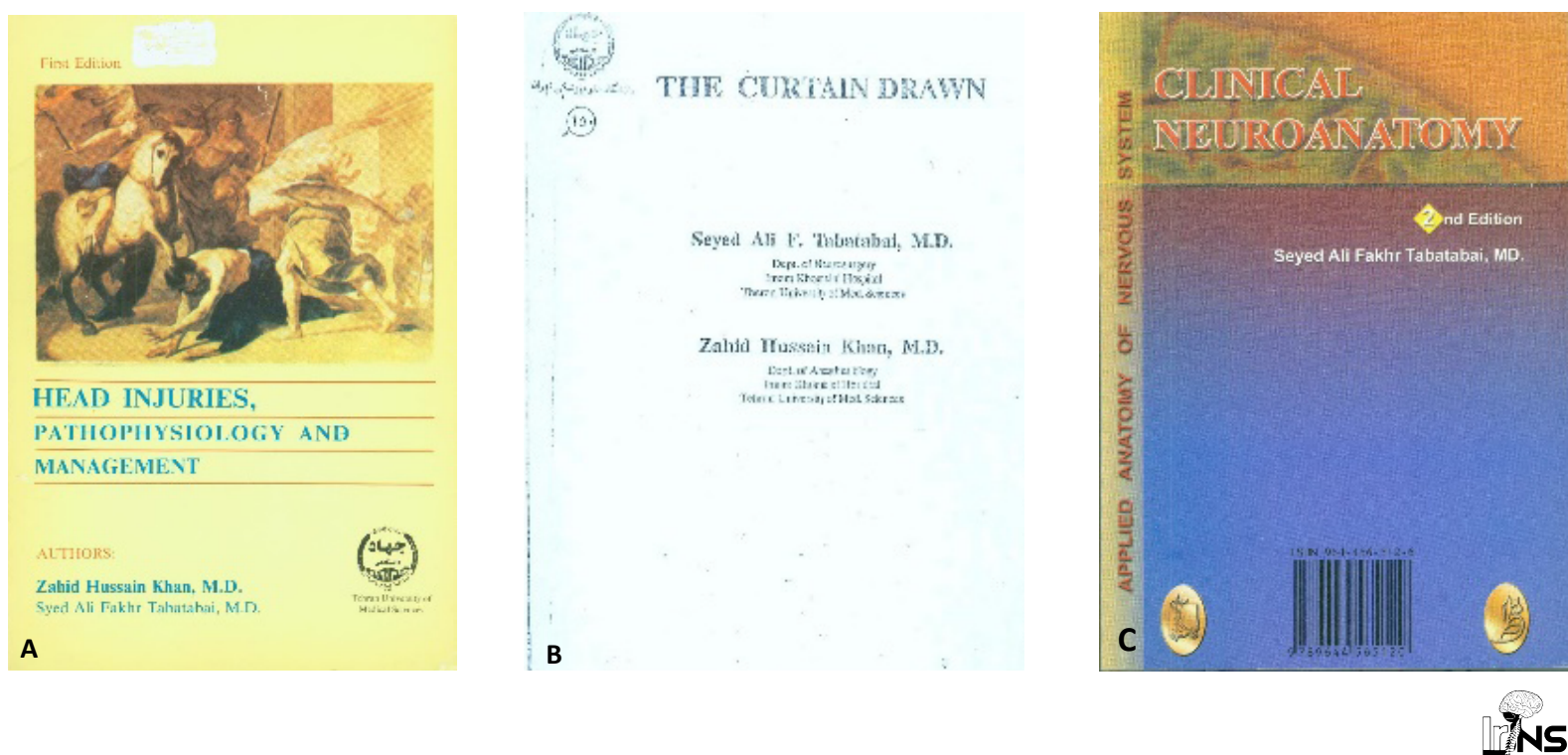

Figure 7. A: Head injuries, Pathophysiology, and Management; B: The Curtain Drawn (In English); C: Clinical Neuroanatomy (In Persian)
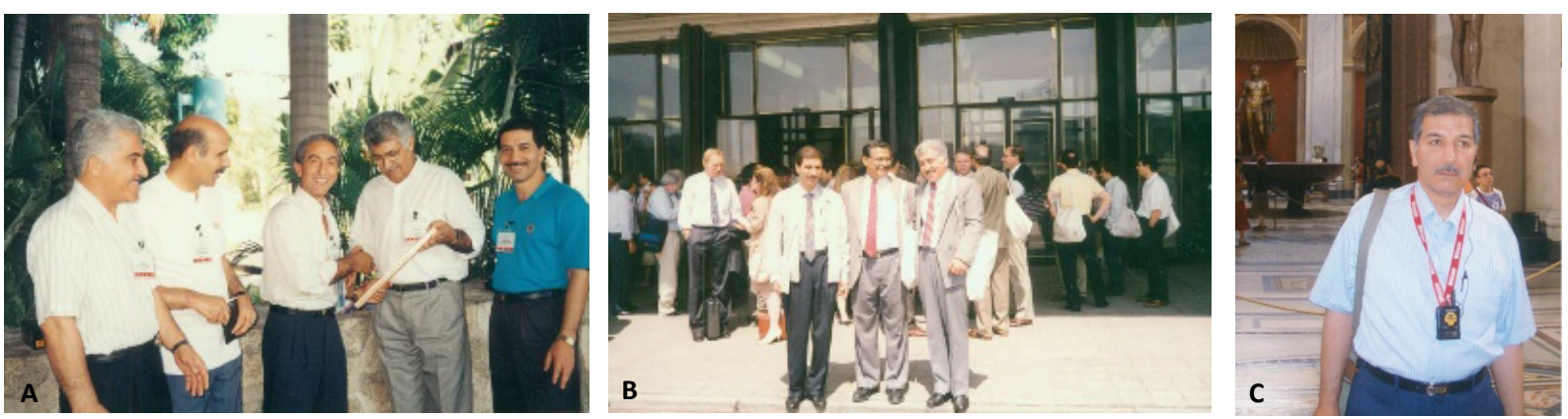

Figure 8. Congress photos abroad

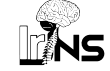

A: In Mexico, from right: Drs. Ali Fakhr Tabatabaei, Hamid Rahmat, Majid Samieii, Mahmoud Tabatabaei, and Zahid Hussain Khan. B: In Moscow, from left: Drs. Ali Fakhr Tabatabaei, Laligam N. Sekhar, and Zahid Hussain Khan; C: In a congress in Italy. 


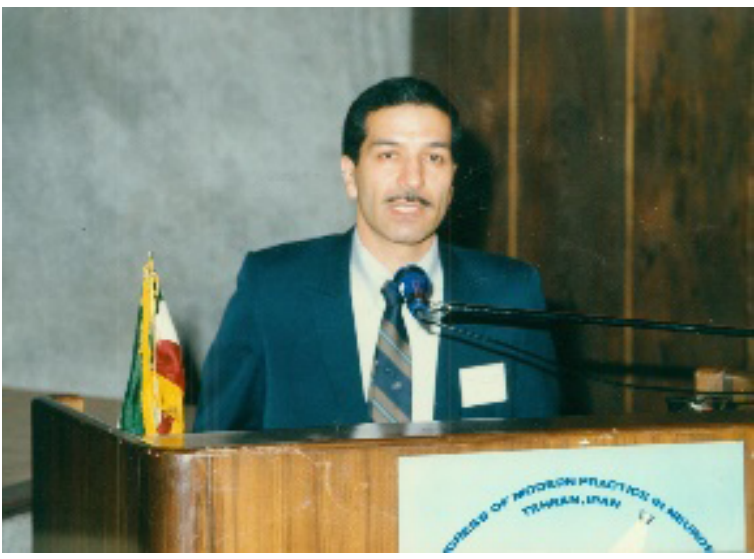

Figure 9. International Congress of Neurosurgery, Laleh Hotel, Tehran.

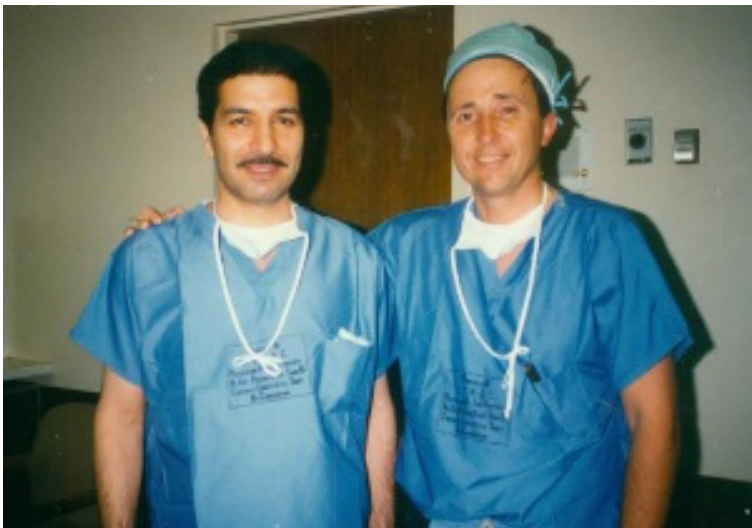

Figure 10. A: With Paul B. Nelson; B: With Laligam N. Sekhar

ters about the management of the ward including the teaching of residents. Likewise, he was well aware of the struggle and efforts put by the nursing staff and would try to compensate for their hard work by giving them certificates of meritorious services (Figure 12).

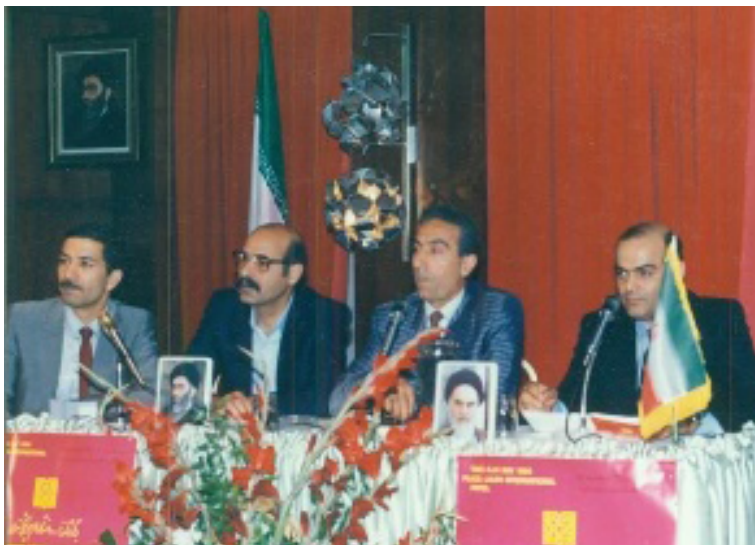

NS

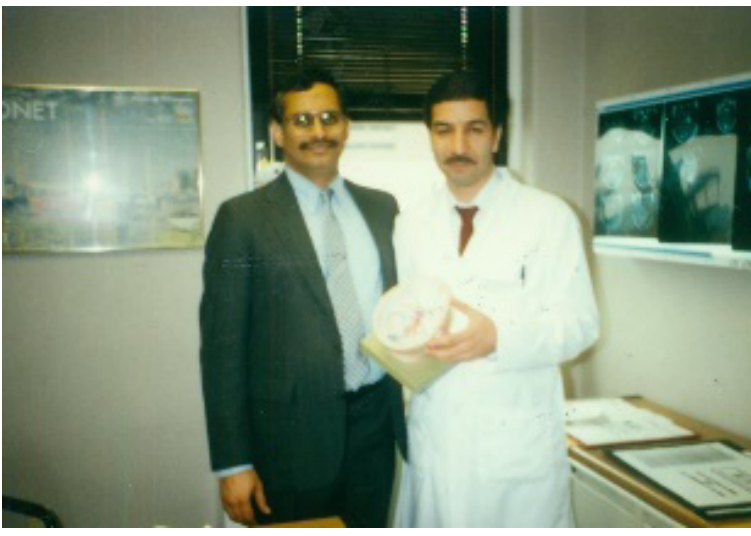

Ins

\section{As a Friend and Colleague}

Some give their hearts, minds, and souls to nurture in their residents, friends, and colleagues, the things that we see as vital to their education, critical for their success in life, and indispensable for their future, and Dr. Tabatabaei was one of them who displayed them all on a silver platter, a trait which very few possess.
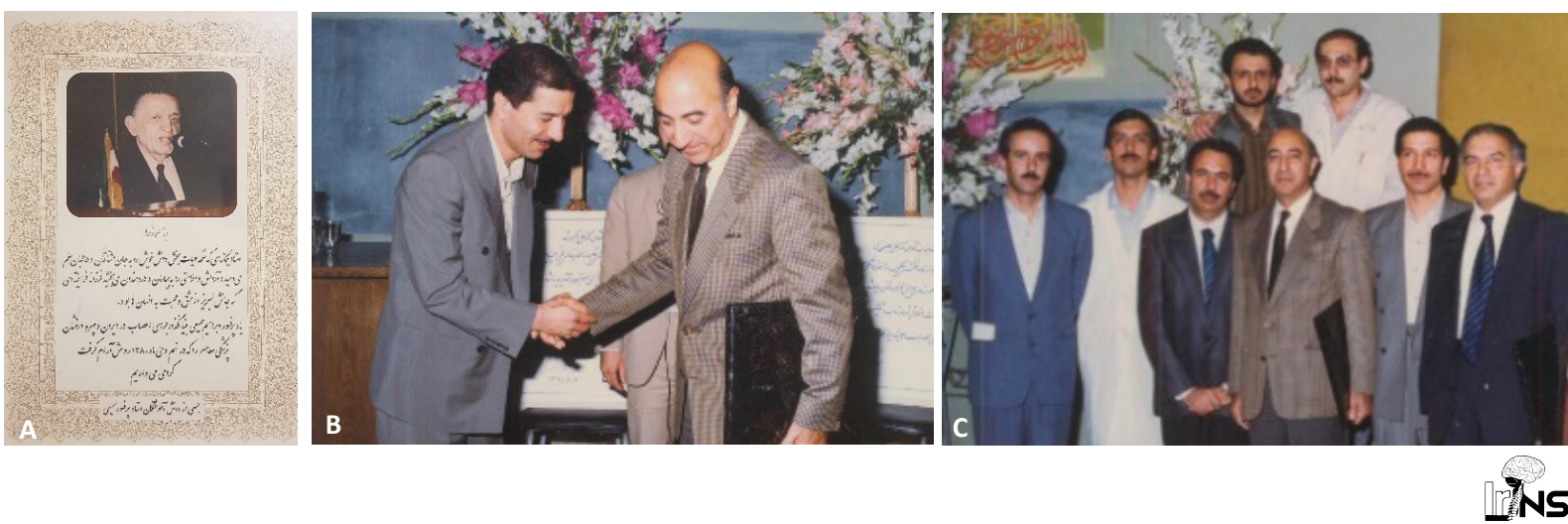

Figure 11. A: Professor Ebrahim Samii, founder of the department; B: In retirement ceremony of Professor Alimohamadi; C: Dr. Tabatabae flanked by professor Murshid and Professor Alimohamadi in a joint photograph of faculty and residents. 


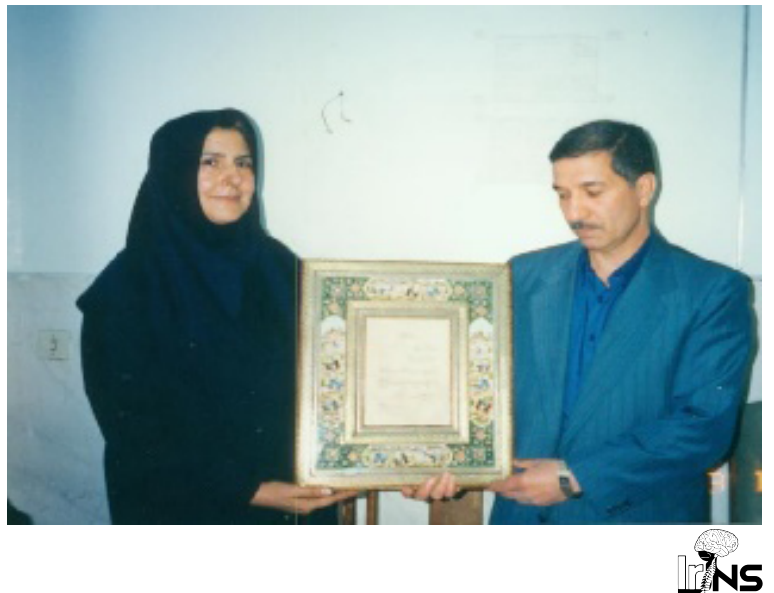

Figure 12. A staff nurse, Mrs. Bordbar, is being awarded a postretirement certificate by Dr. Tabatabaei

The first author (ZHK) was fortunate for having worked with him for almost two and a half decades when he was the head of the department, and not only happily worked with him but at the same time appreciated listening to his analysis of issues ranging from academics to issues of daily life (Figure 13). During discussions, he would always display his phenomenal memory and craftsmanship.

\section{His Dealings With Patients}

These reflected him to be a true Messiah that we find in history. He observed professional ethics in its true spirit and meaning. He was always available for his patients with such a calm and pleasant demeanor. He was thoughtful, compassionate, and devoted to his lofty goals that the patients get the best and optimized care. He would not charge a penny if he had the slightest inkling that his patients belonged to the underprivileged

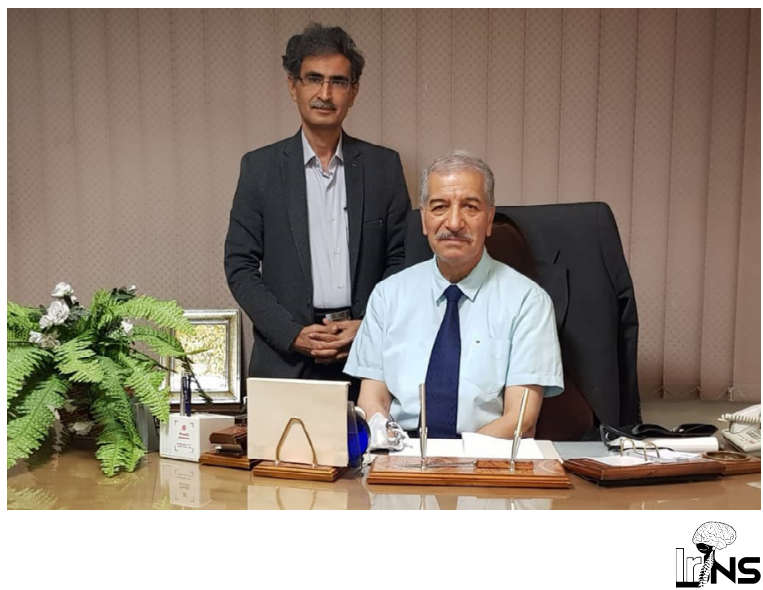

Figure 14. Working at his private office

On the left, the second author (Mehdi Zeinalizadeh) who was his resident from 2001-2007, and currently works as an Associate Professor at Neurosurgical department, IKHC, TUMS.

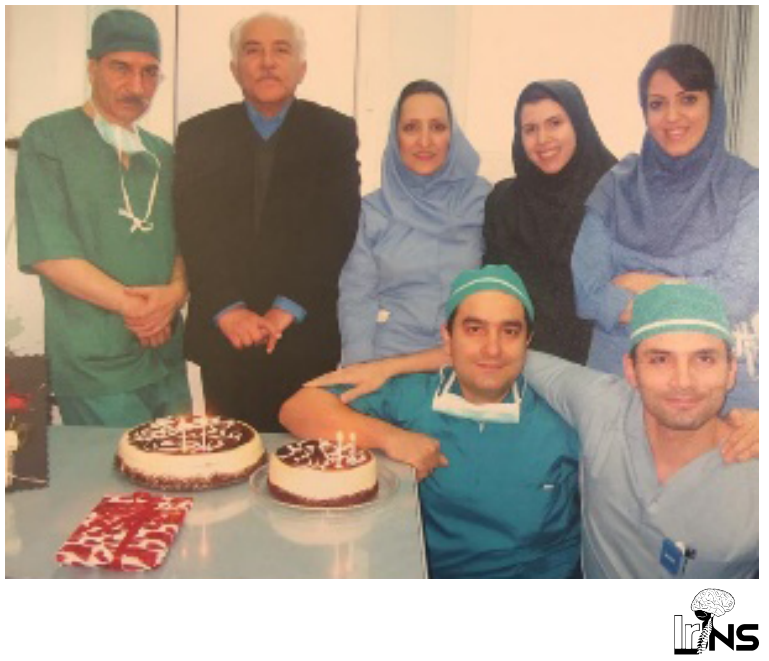

Figure 13. On the birthday anniversary of the first author (Professor Zahid Hussain Khan) in the neurosurgery operating room, Imam Khomeini Hospital Complex (2012)

or deprived strata of the society. Even from the privileged patients, he would charge very nominal fees. He had no conflict of interest whatsoever as for his management of patients was concerned.

\section{Present Position}

Currently, he lives with his wife, makes weekly trips to the nearby mountains, and attends his private clinic thrice a week (Figure 14). Even now whenever he drops in the department, he tries to inculcate that exemplary vision in his colleagues, a habit that he still possesses. $\mathrm{He}$ is active and attends social and academic gatherings when he is invited.

\section{Conclusion}

In conclusion, we wish him a long and peaceful life in the company of his wife, family members, and friends.

\section{Ethical Considerations}

Compliance with ethical guidelines

There were no ethical considerations to be considered in this research.

Funding

This research did not receive any grant from funding agencies in the public, commercial, or non-profit sectors.

\section{Authors' contributions}

Both authors contributed equally to this report article. 


\section{Conflict of interest}

The authors declared no conflict of interest.

\section{References}

[1] Tabatabai A, Jungreis CA, Yonas H. Cervical schwannoma masquerading as a glioma: MR finding. Journal of Computer Assisted Tomography. 1990; 14(3):489-90. [PMID]

[2] Segal R, Alsawaf M, Tabatabai A, Saito R, Segal E, McKinstry $R$. The use of visible light-curing resin for vertebral body replacement. Journal of Neurosurgery. 1991; 75(1):91-6. [DOI:10.3171/jns.1991.75.1.0091] [PMID]

[3] Alsawaf MM, Segal R, Tabatabai A, McKinstry RE. The use of visible light-cured resin system in maxillofacial prosthetics and neuro-orthopedic surgery. Journal of Prosthetic Dentistry. 1991; 66(3):369-76. [DOI:10.1016/0022-3913(91)90265-X]

[4] Tabatabaei SA, Khan ZH. Vein bypass grafts and basofrontal mass lesions. Journal of Neurosurgery. 1991; 74(1):156-7. [DOI:10.3171/jns.1991.74.1.0156] [PMID]

[5] Khan ZH, Tabatabai SAF. Unexplained bradycardia during craniotomy closure: The role of intracranial hypotension. Anesthesia \& Analgesia. 1994; 79(5):1024. [DOI:10.1213/00000539-199411000-00049] [PMID]

[6] Khan ZH, Tabatabaei SA. Complication of catheter knotting following right cephalic vein cannulation. Anesthesia \& Analgesia. 1996; 82(1):215-6. [DOI:10.1213/00000539-19960100000043]

[7] TabatabaeiSA, Zeinalizadeh M, Tayebi Meybodi A, Hashemi M. Extra cranial Aneurysm of the Posterior cerebellar artery with an aberrant origination. Case report. Neurosugery. 2007; 61(5):E1097-8. [ [DOI:10.1227/01.neu.0000303206.92617.07] [PMID]

[8] Tabatabai SAF, Zeinali Zadeh M, Habibi Z, Tayebi Meybodi A, Hashemi M. Intracranial atypical calcification in nongalenic pial arteriovenous fistula: A case report. Cases Journal. 2008; 1(1):335. [DOI:10.1186/1757-1626-1-335] [PMID] [PMCID] 


\section{Comments}

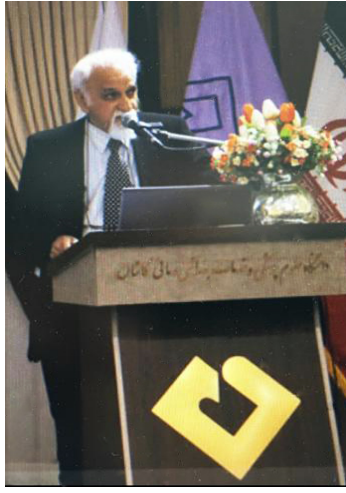

Moosa Taghipour, MD

Professor of Neurosurgery, Faculty of Neuroscience, Shiraz University of Medical Sciences, Fars, Iran

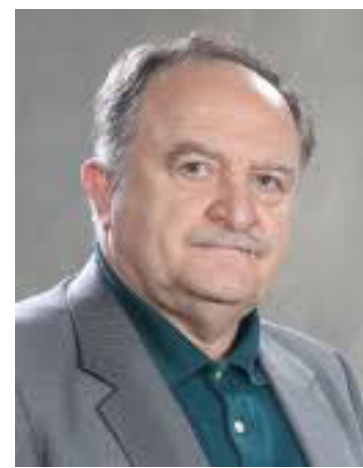

Abbas Amirjamshidi, MD

Professor of Neurosurgery, Faculty of Medicine, Tehran University of Medical Sciences, Tehran, Iran

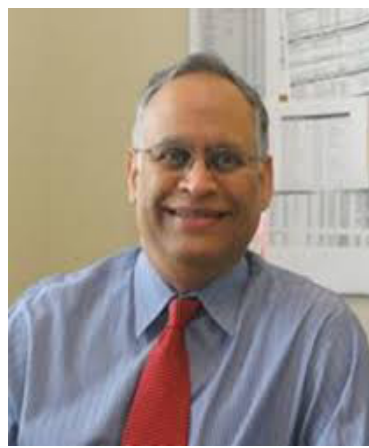

Laligam N Sekhar, MD.

FACS, FAANS, Professor and Vice-chairman, Department of Neurosurgery Director, Cerebrovascular Surgery Director, Skull Base Surgery; University of Washington, Seattle, WA, USA
This is a great honor to write a tribute to Professor Ali Fakhr Tabatabaei. He has had a great impact on the history of neurosurgery in our country. He can be called a pioneer in the field of surgical treatment of patients with neurovascular compression, for instance, trigeminal neuralgia, hemifacial spasm, and essential hypertension in Iran.

Dr. Tabatabaei always loved teaching, especially neuro-anatomy. He has a brilliant book in this field. He believed that the neuroanatomy is the base of neurosurgery and gave priority to this query in teaching to residents.

Professor Tabatabaei has always been committed to moral awareness in his professional role and focused on human dignity. He was indeed open to criticism. In summary, Professor Ali Fakhr Tabatabaei is an influential neurosurgeon in practice as well as training in Iran.

"The right bus with the right people on it can be headed in the right direction" and Dr. Seyed Ali Fakhr Tabatabaei tried his best to lead a strong alignment of the neurosurgeons in his department with the institutional aims of outstanding care, research, and teaching, with all of the infrastructures in place.

It has always been a great pleasure for me knowing Prof. Fakhr Tabatabaei, not only as a friend and colleague but a perfect neurosurgeon and the man with the capability to create the atmosphere for others to succeed and could play the role of the leader and trouble-shooter in difficult medical and official situations.

I came to know Professor Ali Tabatabei very well when I was at the University of Pittsburgh Medical Center, while he did a fellowship under the mentorship of Professor Peter Jannetta. At that time, I found him a very good neurosurgeon, very industrious and studious and constantly learning the science and art of Neurosurgery. $\mathrm{He}$ and I had many conversations about Neurosurgery, life in Iran, and our shared heritage of Indian and Persian culture, and food. I found him to be an outstanding individual, one who will make a mark on Iranian Neurosurgery in the future. After he returned to Iran, he and I kept in touch, and he shared many of his cases (operated) and experiences with me. I found that he had matured into a great Neurosurgeon. I heard more about him through his students. I have read the current article about his life and achievements by Mehdi Zeinalizadeh, and find it to be a very fitting tribute to this great neurosurgeon and teacher. He is clearly one of the giants of Neurosurgery in Iran. 